\title{
The comparison of the kinds of mental-social stresses of teaching hospitals' nursing staff in Birjand between 2004 and 2014
}

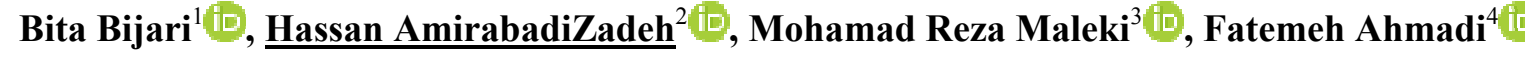 \\ ${ }^{1}$ Cardiovascular Diseases Research Center, Department of community Medicine, Birjand University of Medical Sciences, Birjand, \\ Iran. \\ ${ }^{2}$ Corresponding author; Social Determinant of Health Research Center, Birjand University of Medical Sciences, Birjand, Iran. \\ Tel: $05632395690 \quad$ E-mail: hassanamirabadi@yahoo.com \\ ${ }^{3}$ Health Management and Economic Sciences Research Center, Faculty Health Management and Economic Sciences, Iran \\ University of Medical Sciences, Tehran, Iran. \\ ${ }^{4}$ Department of English Language, Islamic Azad University of Torbat Heidarieh, Torbat Heidarieh, Iran
}

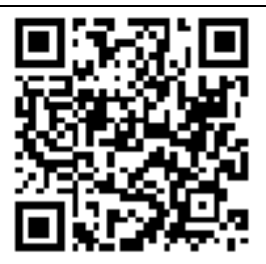

Citation Bijari B, AmirabadiZadeh H, Maleki MR, Ahmadi F. [The comparison of the kinds of mental-social stresses of teaching hospitals' nursing staff in Birjand between 2004 and 2014]. J Birjand Univ Med Sci. 2019; 26(1):74-82. [Persian]

DOI http://doi.org/10.32592/JBirjandUnivMedSci.2019.26.1.108

Received: February 14, 2018

Accepted: July 29, 2018

\begin{abstract}
Background and Aim: Nursing is one of the most stressful jobs. The high level of stress affects the physical and mental health of nurses and their job performance. The purpose of this study is comparing the psychosocial stresses of the nursing staff of the educational hospitals in Birjand between 2004 and 2014.

Materials and Methods: In this cross-sectional study, 306 nursing staff of educational hospitals (Imam Reza and Vali-e-Asr) in Birjand city were selected by census and studied. Then, the results of this study were compared with the results of a study done in 2004 on 247 nursing staff of Imam Reza and Vali-e-Asr hospitals of Birjand for this purpose. The data collection method was a researcher-made questionnaire consisting of 85 questions in three sections of personal stress, family and work environment that was completed by the Data were collected by SPSS software (version 16) and analyzed by independent t-test at a significant level of $\alpha<$ 0.05 .

Results: The mean of stress score in the year 2004 was $3.11 \pm 1.25$ and in the year 2014 was $3.03 \pm 1.15$. This difference was not statistically significant $(\mathrm{P}=0.44)$. The stress caused by family factors and work environment in 2014 was significantly lower than in $2004(\mathrm{P}=0.02, \mathrm{P}=0.005)$. However, the stress was not due to personal factors between two years. $(\mathrm{P}=0.12)$.

Conclusion: Although the level of stress in the nursing staff of educational hospitals has fallen more than 10 years ago, it still has a high level.
\end{abstract}

Key Words: Stress; Hospital; Nurse 


\title{
مقايسه انواع استرسهاى روانى-اجتماعى كادر يرستارى بيمارستانهاى

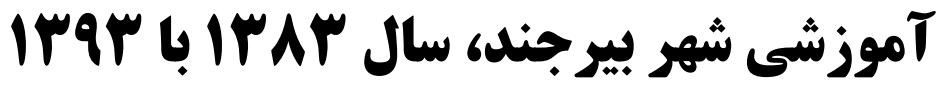

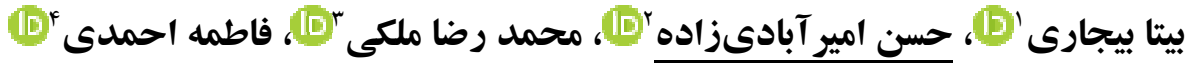

\section{جكيده}

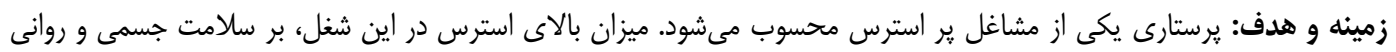

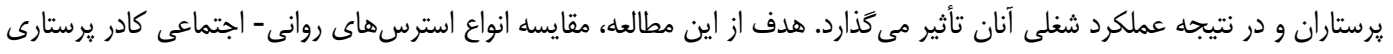

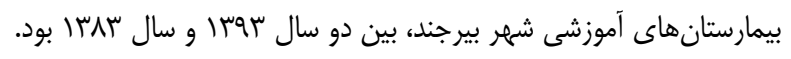

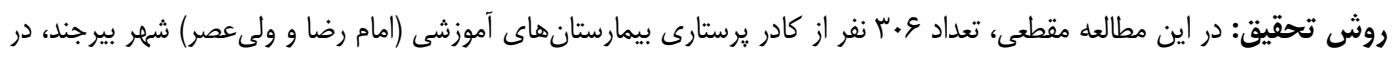

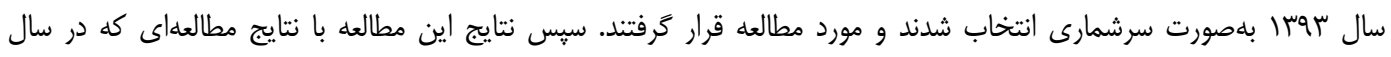

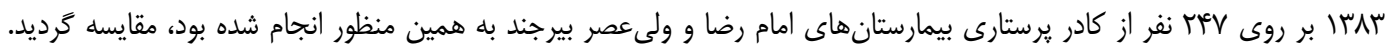

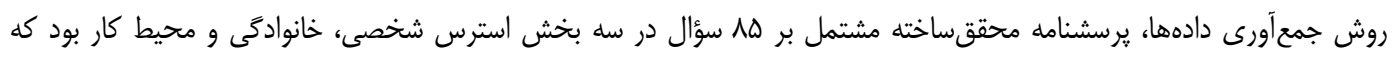

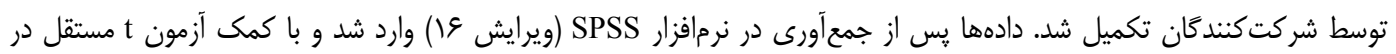

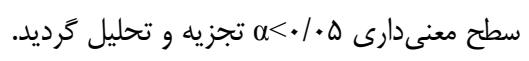

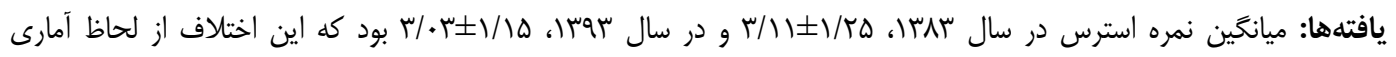

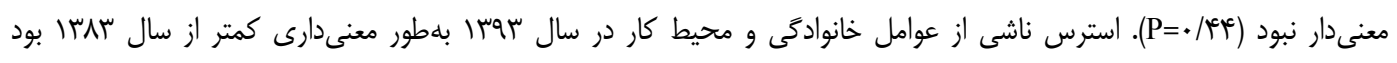

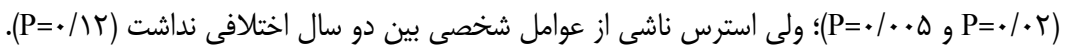

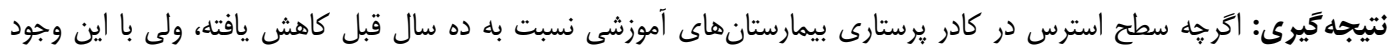
هنوز از سطح بالايى برخوردار است.

$$
\text { وازههاى كليدى: استرس؛ بيمارستان؛ يرستار }
$$

مجله علمى دانشكاه علوم يزشكى ييرجند. A

$$
\text { دريافت: }
$$

' ' مركز تحقيقـات بيمارىهاى قلب و عروق، كروه يزشكى اجتماعى، دانشكاه علوم يزشكى بيرجند، بيرجند، ايران

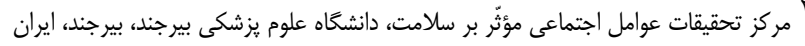

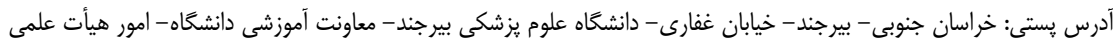

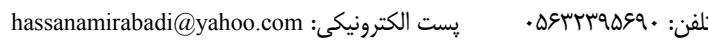

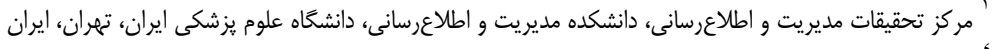

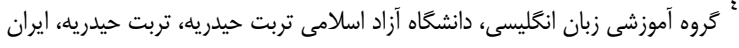


مديران، عدم توافق با مديران، كمبود تعداد يرسنل، افزايش

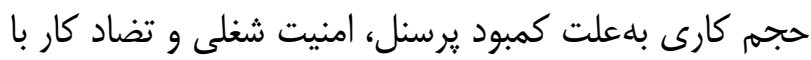
خانه است (^). يرستاران بلهدليل ماهيت حرفهاى خودئ خود بلهطور

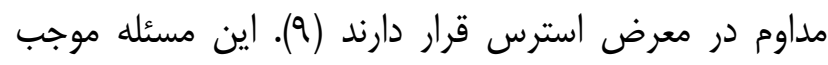

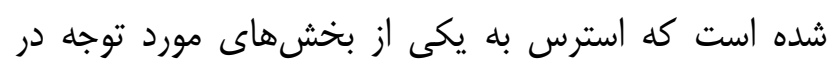
مطالعات يرستارى تبديل شود (• (1).

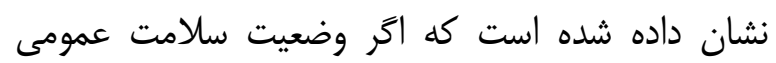

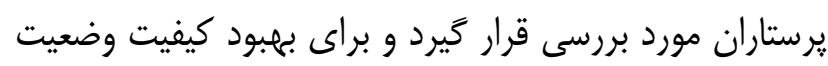

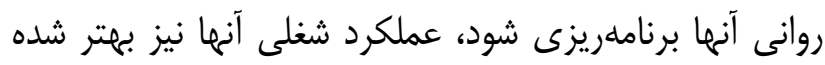

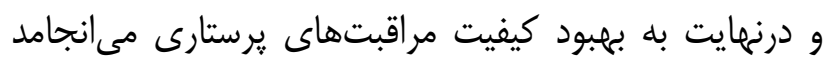

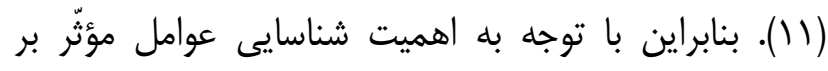

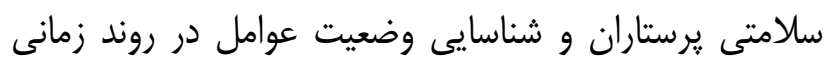

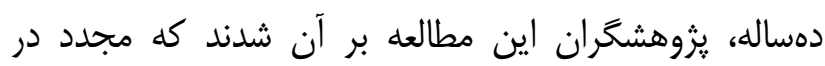

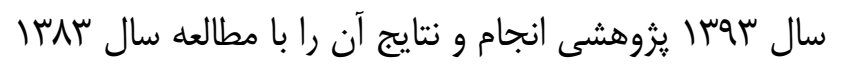
مقايسه نمايند.

\section{روش تحقيق}

در اين مطالعه مقطعى (توصيفى - تحليلى)، كادر يرستارى

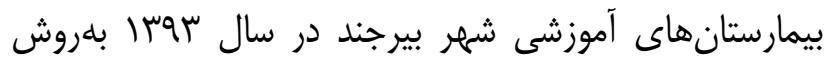

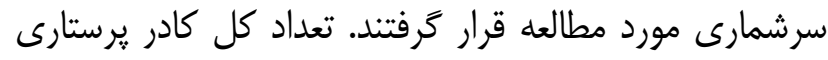

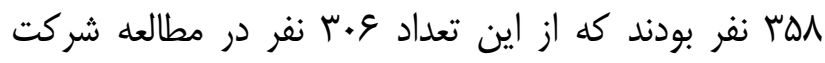

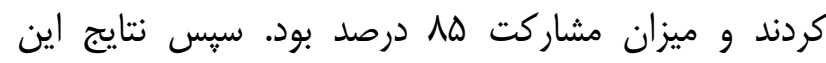

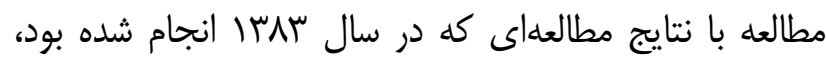

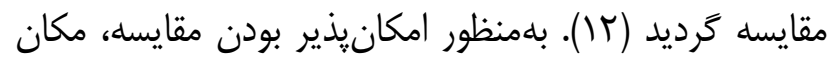

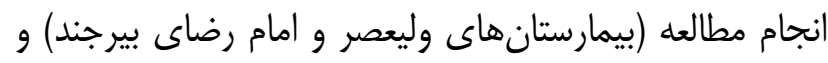
نيز وضعيت استخدامى و عوامل ساختارى و وظيفهاى مطالعه واله

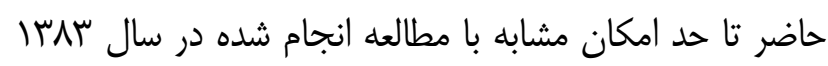
در نظر گرفته شد. روش جمعآورى دادهها در هر دو مقطع زمانى سالهاى

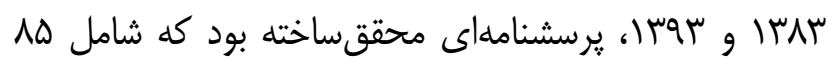
سؤال در ع بخش مشخصات دموگرافيك و كارى (1) سوال)،

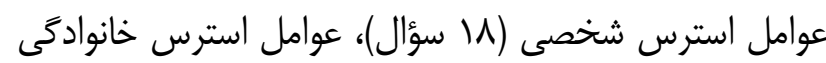

مقدمه

استرس يكى از عوامل مهم ايجاد عوارض جسمى و

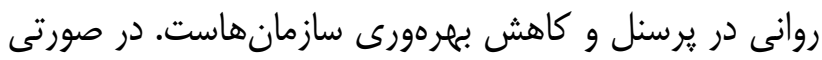
كه استرس كارى بهدرستى مديريت نشود، مى بوانو كاند كيفيت كار كاركنان و سلامت روانشناختى آنها را تحت تأثير قرار دهد (1). در دهلى اخير استرس بلهعنوان يكى از مان مهمترين

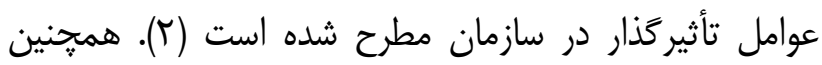

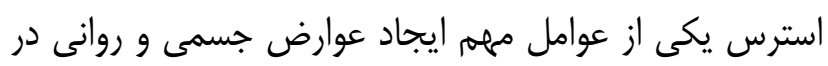

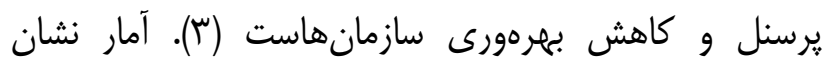
مىدهد كه تنها در كشور آمريكا نزديك به به ل| لا ميليون نفر از استرس شغلى رنج مىبرند. در طى ثروهش ديخرى نزديك به

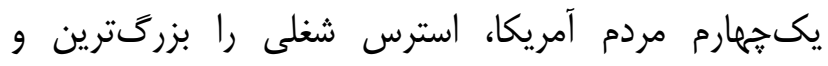
مهمترين مشكل در زندگى قلمداد كردهاند (أ).

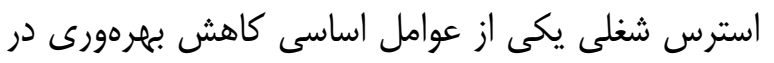
سازمانها و ايجاد عوارض جسمى و روانى در كاركنان است.

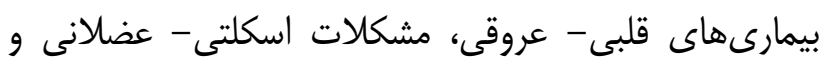

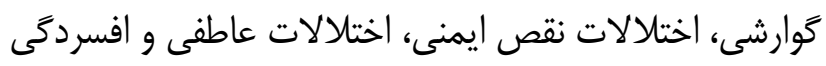

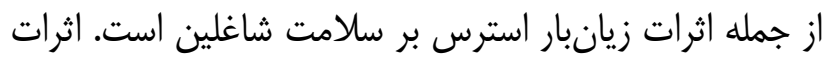

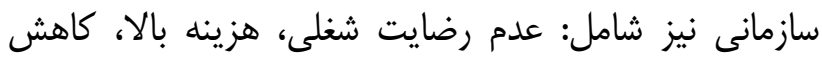
عملكرد، افزايش غيبت از كار و افزايش حوادث شغلى سلى است كهاب خود بار مالى و عاطفى وسيع بر جامعه و فرد تحميل مى كند

يرستارى يك شغل بسيار ير استرس محسوب مى شود.

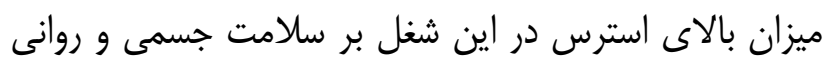

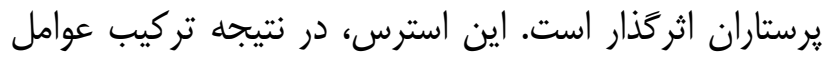

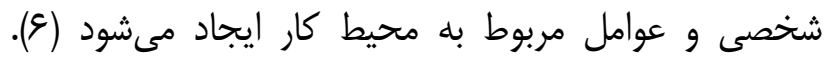
استرس و رضايت شغلى از جمله عوامل تأثيركذار بر كارآيى

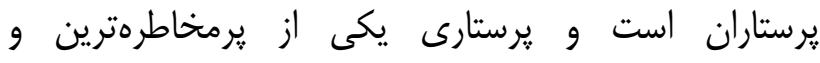

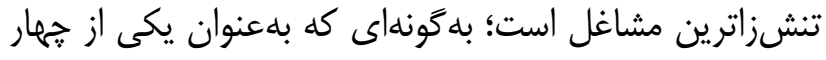

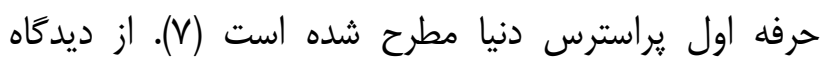

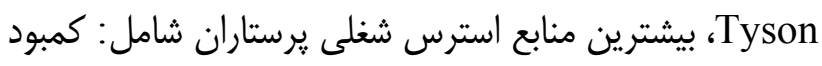

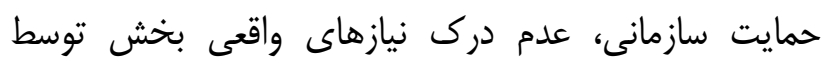


t توصيفى (ميانغين، انحرافمعيار، درصد و فراوانى) و آزمون

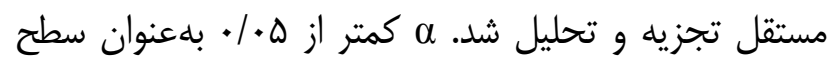
معنى دارى در نظر كرفته شد.

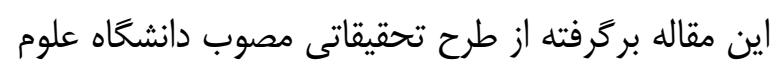

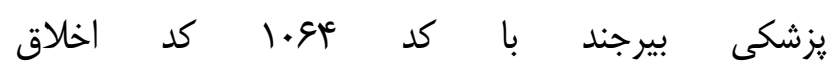
Ir.bums.REC.1394.407 مىباشد.

يافتهها در اين مطالعه تعداد צ.ّ نفر از كادر يرستارى در سال

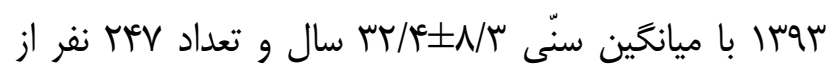

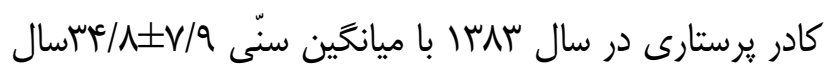

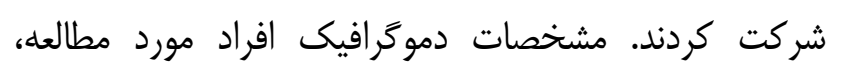
محل كار و وضعيت استخدامى شركت كنندكان در سال سربـا و سال سوسا در جدول يك نشان داده شده است. ميانخين نمره استرس عوامل شخصى در مردان در سال

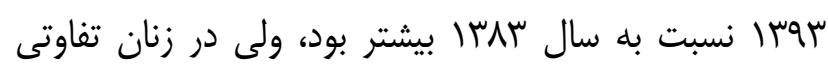

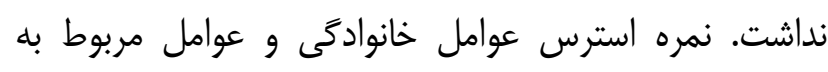
محيط كار در زنان، در سال سوسا نسبت به سال سمبس كا كمتر

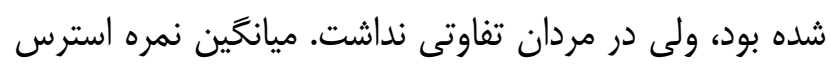

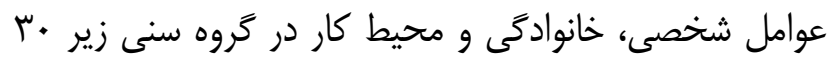

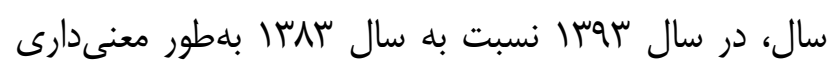

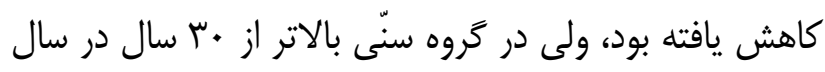

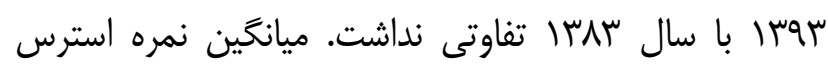

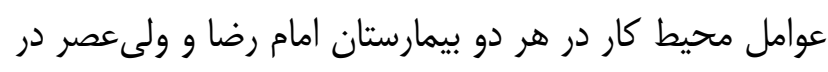

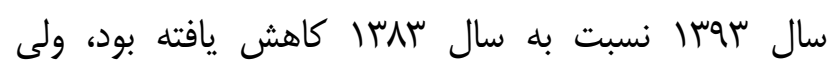

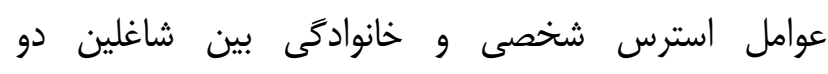

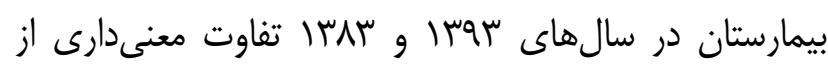

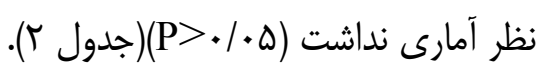
نتايج يزوهش حاضر نشان داد كه در سال سربا، ميزان

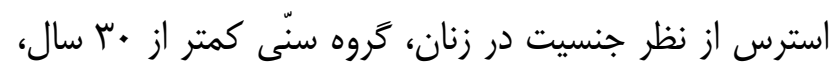
وضعيت استخدام غيررسمى بلهطور معنىدارى بالاتر از مردان

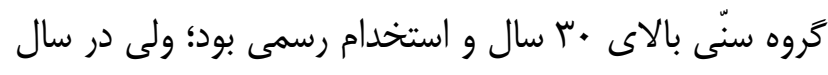

(9 سؤال) و عوامل استرس در محيط كار (•^أوأل) بود. در

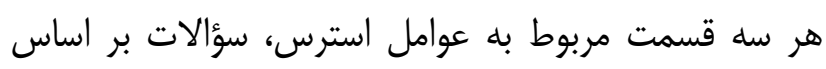

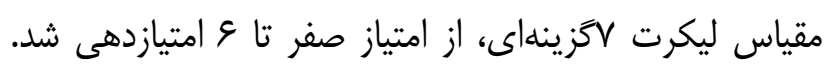
براى هر فرد، مجموع نمرات كسبشده بر تعداد سؤالات هر

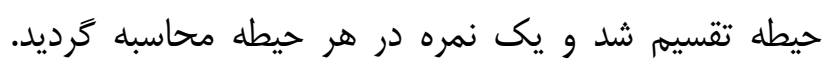
دامنه نمرات كسبشده، بين صفر تا وبود.

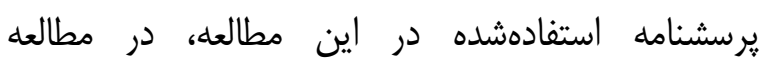

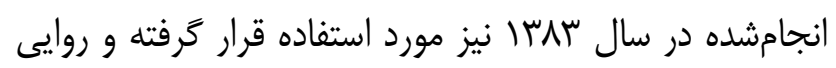

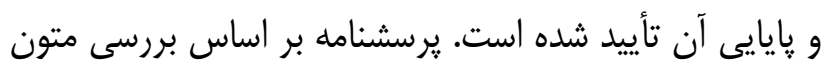

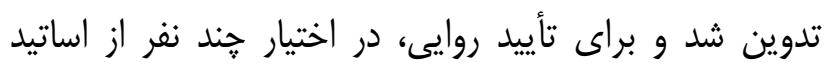

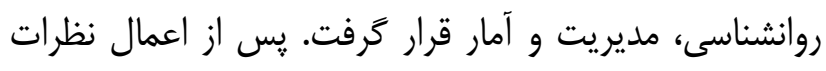

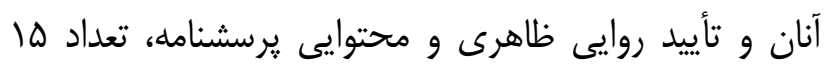

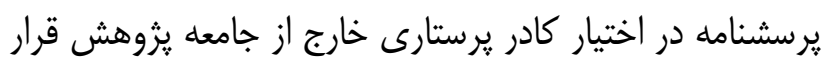

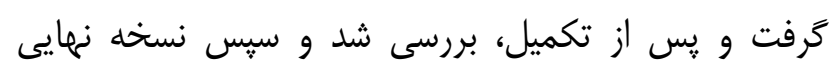

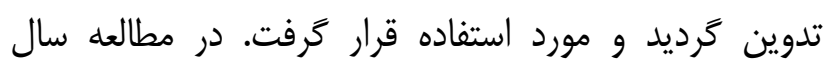

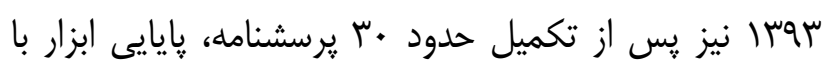

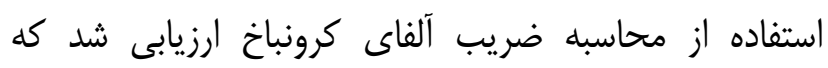

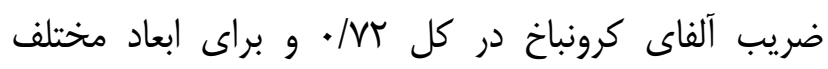

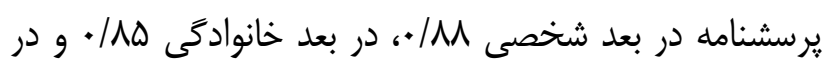
بعد محيط كار و 9/ • بهدست آمد.

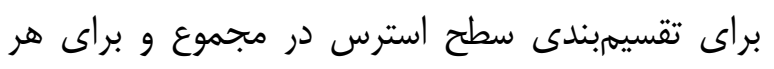

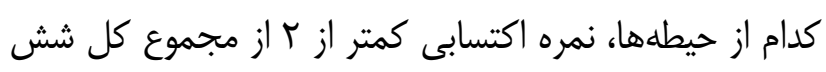

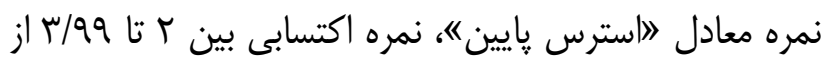

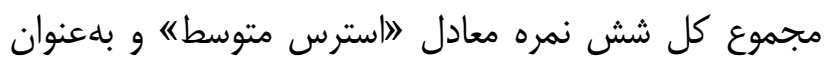

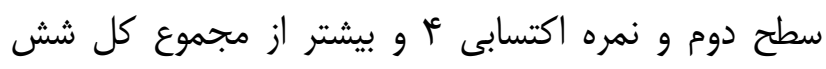

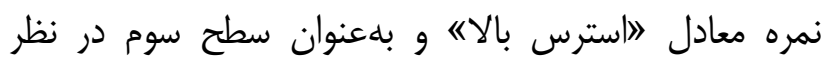
كرفته شد. ابتدا در خصوص اهداف طرح براى شركت شكندان توضيح داده شد. سيس يرسشنامه بين كادر يرستارى دو

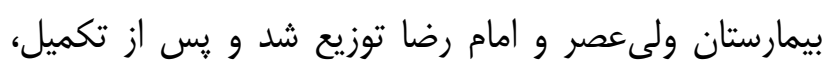

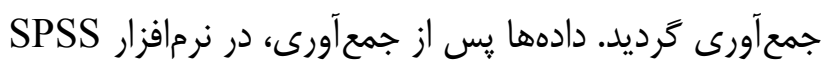

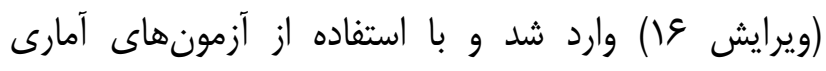




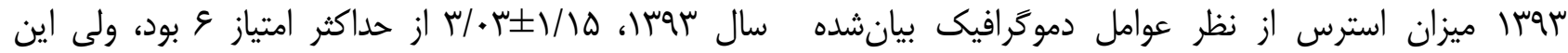

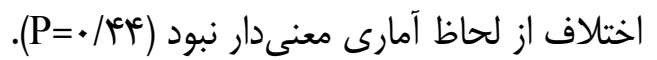

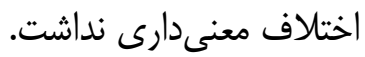

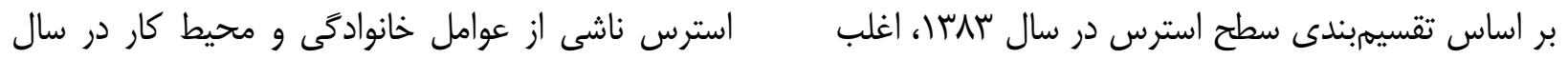

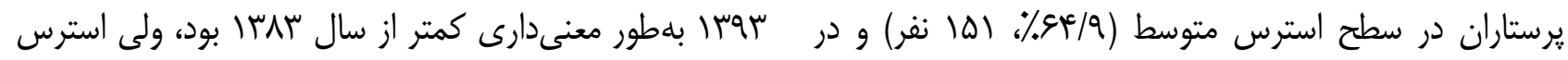

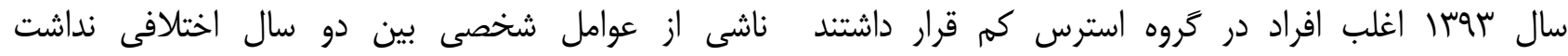

$$
\text { (P=.//r) }
$$

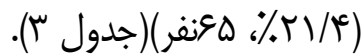

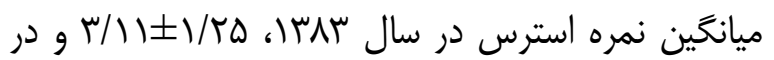

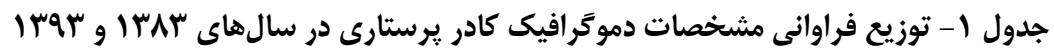

\begin{tabular}{|c|c|c|c|}
\hline سال سوسו & سال س^זו & \multirow{2}{*}{ مشخصات } & \multirow{4}{*}{ بيمارستان } \\
\hline (درصد) تعداد & ) (درصد) تعداد & & \\
\hline $10 \cdot(199)$ & $V I(T N / Q)$ & بيمارستان امام رضا(ع) & \\
\hline $\operatorname{l\Delta g}(\Delta \mid)$ & $\operatorname{IVg}(\mathrm{V} / \mathrm{l})$ & بيمارستان وليعصر (عج) & \\
\hline$\Delta v(1 N / 9)$ & $f(18 / 9)$ & 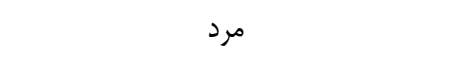 & \multirow{2}{*}{ جنس } \\
\hline$r \in a(\wedge) / \Lambda)$ & $r \cdot q(\Lambda \mu / \mathcal{F})$ & زن & \\
\hline $\operatorname{IrT}(\mp \Delta / \Delta)$ & $\wedge q(r g / r)$ & ا r تا وب سال & \multirow{4}{*}{ كروه سنى } \\
\hline$\wedge q(\mu) / v)$ & $V I(Y N / Q)$ & 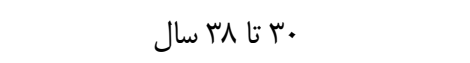 & \\
\hline$\Delta q(\Gamma \cdot / \mu)$ & $\operatorname{vg}(\mu \cdot / \varepsilon)$ & qץ تا Vץז سال & \\
\hline $1 \cdot(\varphi / \mu)$ & $11(\% / \mu)$ & 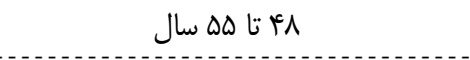 & \\
\hline$\Delta \cdot(1 \varepsilon / \Gamma)$ & $V q(r T / 1)$ & شيفت ثابت & \multirow{2}{*}{ 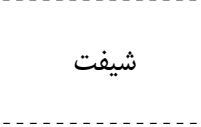 } \\
\hline$r \Delta \mathcal{S}(\wedge \Gamma / \mathrm{V})$ & $19 \wedge(9 \vee / 9)$ & شيفت در گردش & \\
\hline$r M(\& N / q)$ & $\operatorname{If} \Delta(\Delta N / 9)$ & كاردان و كارشناس يرستارى & \multirow{4}{*}{ 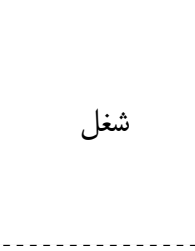 } \\
\hline$\Delta S(\backslash \Lambda)$ & $10(\xi /)$ & كاردان و كارشناس اتاق عمل و هوشبرى & \\
\hline$r \Delta(\Lambda / \mathscr{r})$ & $\operatorname{sV}(T V / 1)$ & 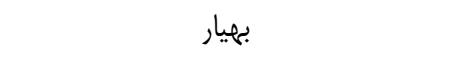 & \\
\hline$I F(F / V)$ & $r \cdot(N / T)$ & كمكى بهيار & \\
\hline$\| \varepsilon($ rV/q) & $\operatorname{lr}(99 / \wedge)$ & رسمى & \multirow{4}{*}{ وضعيت استخدامى } \\
\hline$r r(1 \cdot / 0)$ & $\mid r(\Delta / \mu)$ & ييمانى & \\
\hline$\Delta \Psi(I V / \mathcal{F})$ & $\Delta q(K r / V)$ & طرحى & \\
\hline $1 \cdot \Delta(\mu F / T)$ & $r(1 / r)$ & 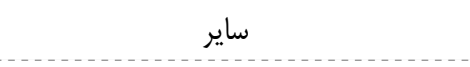 & \\
\hline$r \& \mid(\Lambda \bowtie / r)$ & $199(\Lambda \cdot / v)$ & 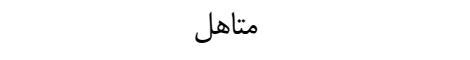 & \multirow{3}{*}{ وضعيت تأهّل } \\
\hline$F \cdot(1 r / F)$ & $\operatorname{rr}(\mathrm{IV} / \mathrm{G})$ & 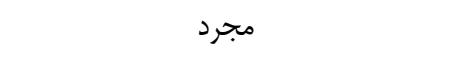 & \\
\hline$r(1 / r)$ & $f(1 / 9)$ & بيوه و مطلقه & \\
\hline
\end{tabular}


جدول r- مقايسه ميانكَين نمره استرس بر حسب مشخصات شر كت كنندًان و بيمارستان

\begin{tabular}{|c|c|c|c|c|}
\hline سطح معنى دارى آزمون & (انحر افمعياردميانكَين) & (انحر افمعياردميانكَين) & مشخصات & \\
\hline$\cdot 1 \cdot 1$ & $r / \wedge q \pm / / 1 r$ & $r / \cdot V \pm I / \cdot V$ & زن & \\
\hline \multirow[t]{2}{*}{$<\cdot / \bullet 1$} & $r / g r \pm 1 / 1 r$ & $r / \uparrow \wedge \pm \cdot / q \vee$ & 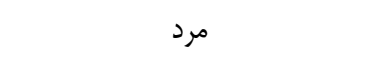 & عوامل شخصى \\
\hline & .119 & $\cdot 1 \cdot+r$ & سطح معنىدارى آزمون تى مستقل & \\
\hline $.1 \cdot c^{c}$ & $r / q \Gamma \pm 1 / \Delta \Delta$ & $r / Q \varphi \pm 1 / \Delta r$ & 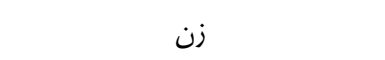 & \\
\hline \multirow[t]{2}{*}{$\cdot / \Delta \Lambda$} & $r / r V \pm I / ז \oplus$ & $r / T^{A} t \pm I / T$ & 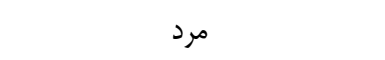 & عوامل خانوادگى \\
\hline &.$/ 14$ & $.1 \cdot 0$ & سطح معنىدارى آزمون تى مستقل & \\
\hline$<\cdot / \cdot 1$ & 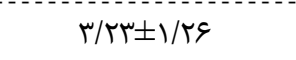 & 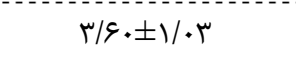 & 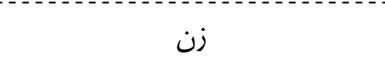 & \\
\hline \multirow[t]{2}{*}{.$|\Delta|$} & 每 & $r / \cdot q \pm 1 / \cdot \Lambda$ & 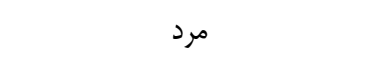 & عوامل محيط كار \\
\hline & .119 & $.1 \cdot r$ & سطح معنىدارى آزمون تى مستقل & \\
\hline$<\cdot 1 \cdots 1$ & $r / \Lambda \mid \pm 1 / /)^{c}$ & $r / \Gamma \Delta \pm \cdot / 9 \vee$ & كروه سنى زير •r سال & \\
\hline \multirow[t]{2}{*}{.$/ 9 V$} & $r / \Lambda \mu \pm 1 / \cdot q$ & $r / \wedge \mu \pm 1 / \cdot r$ & عروه سنى •ـ سال و بالاتر & عوامل شخصى \\
\hline & .119 & $\cdot 1 \cdot+1$ & سطح معنىدارى آزمون تى مستقل & \\
\hline $.1 \cdot .9$ & $r / \kappa q \pm / / \Delta q$ & $r / . q \pm 1 / q r$ & عروه سنى زير •r سال & \\
\hline \multirow[t]{2}{*}{.$/ 9$} & $r / \Delta q \pm 1 / r q$ & $r / \varepsilon \mid \pm 1 / 4 r$ & كَروه سنى •r سال و بالاتر & عوامل خانوادگى \\
\hline & .109 & .1 .9 & سطح معنىدارى آزمون تى مستقل & \\
\hline$<\cdot 1 \cdot+1$ & r & 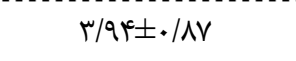 & كروه سنى زير • س سال & \\
\hline \multirow[t]{2}{*}{ س4 } & 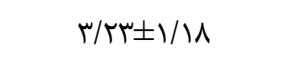 & 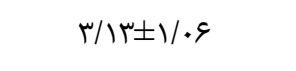 & گروه سنى •"ّ سال و بالاتر & عوامل محيط كار \\
\hline &.$/ 199$ & $\cdot 1 \cdot+1$ & سطح معنى دارى آزمون تى مستقل & \\
\hline$\cdot /$ / & $r / g r \pm 1 / /)^{c}$ & $r / \vee \wedge \pm 1 / \cdot \varphi$ & بيمارستان امام رضا & \\
\hline \multirow[t]{2}{*}{$\cdot /$ /AV } & $r / \cdot \Delta \pm 1 / \cdot V$ & $r / \cdot v \pm 1 / \cdot q$ & بيمارستان ولى عصر & 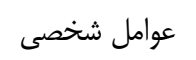 \\
\hline & $\cdot 1 \cdot+t^{\mathrm{c}}$ & .1 .9 & سطح معنى دارى آزمون تى مستقل & \\
\hline .1 .9 & $r / r \wedge \pm 1 / R \Delta$ & $r / V \wedge \pm 1 / R \varepsilon$ & بيمارستان امام رضا & \\
\hline \multirow[t]{2}{*}{.$/ 4 \lambda$} & $r / V F \pm 1 / \Delta q$ & $r / \wedge \varepsilon \pm 1 / r q$ & بيمارستان ولى عصر & عوامل خانوادگى \\
\hline & $\cdot 1 \cdot 0$ & .198 & سطح معنىدارى آزمون تى مستقل & \\
\hline.$/ . r$ & $r / 99 \pm 1 / 4 r$ & 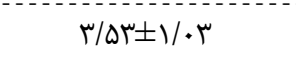 & بيمارستان امام رضا & \\
\hline \multirow[t]{2}{*}{$\cdot 1 \cdot+\Delta$} & $r / \varepsilon q \pm 1 / 1 r$ & $r / \backslash \Delta \pm 1 / \cdot V$ & بيمارستان ولى عصر & عوامل محيط كار \\
\hline &.$\mu r$ &.$/ 19$ & سطح معنىدارى آزمون تى مستقل & \\
\hline
\end{tabular}




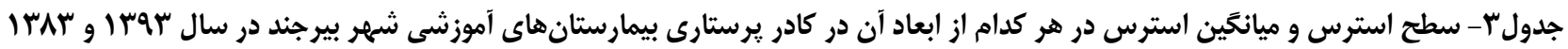

\begin{tabular}{|c|c|c|c|c|c|c|c|c|}
\hline \multicolumn{2}{|c|}{ مجموع } & \multicolumn{2}{|c|}{ عوامل محيط كار } & \multicolumn{2}{|c|}{ عوامل خانوادَىى } & \multicolumn{2}{|c|}{ عوامل شخصى } & \multirow[b]{2}{*}{ سطح استرس) } \\
\hline 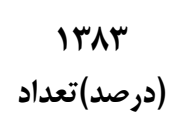 & 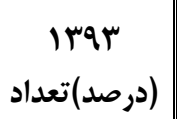 & 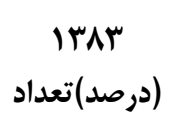 & (درصد) تعداد & 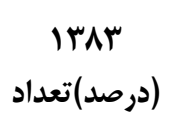 & 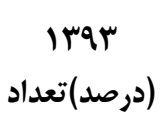 & 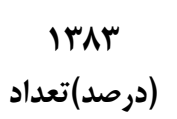 & 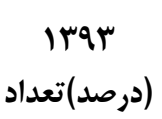 & \\
\hline$M F(I F / T)$ & $9 Q(\% / r \backslash / F)$ & $r)(q / I)$ & Q) $(\% \backslash \xi / V)$ & $V \Delta(\Psi) / Q)$ & $|r|(\%$ \%q/ه) & $r \Delta(19)$ & $V \wedge(T \Delta / \&)$ & سطح استرس كم \\
\hline$|0|(94 / 9)$ & $\operatorname{IVT}(\% \Delta \& / \varepsilon)$ & 更 & $1 \varepsilon \Delta(\Delta \Gamma / \Lambda)$ & $q \varepsilon(F \cdot / q)$ & 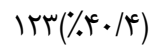 & $1 F q(g r / q)$ & $|\Lambda|\left(\Delta Q /{ }^{c}\right)$ & سطح استرس متوسط \\
\hline $\operatorname{lq}(r \cdot / q)$ & $S V(T r)$ & $V^{\mu}\left(\mu^{\prime} / \Lambda\right)$ & $q \cdot(r q / 8)$ & $g r(T Y / T)$ & $91(\% \cdot r \cdot)$ & TH(IN/I) & $\Leftrightarrow(10)$ & سطح استرس زياد \\
\hline$\Gamma / \| \pm I / \Gamma \Delta$ & $r / \cdot r \pm 1 / / \Delta$ & $\Gamma / \Delta \mid \pm 1 / .9$ & & $r / \Lambda \notin \pm I / \mathcal{C} V$ & $r / \Delta \& \pm 1 / \Delta T$ & $r / 9 q \pm 1 / . q$ & $r / \Lambda \uparrow \pm I / I r$ & انحراف معيار 土ميانكين \\
\hline \multicolumn{2}{|c|}{$\cdot / 4$} & \multicolumn{2}{|c|}{$\cdot 1 \cdot 0$} & \multicolumn{2}{|c|}{. } & \multicolumn{2}{|c|}{.$/ T$} & $\begin{array}{c}\text { سطح معنى دارى آزمون } \\
\text { T-test }\end{array}$ \\
\hline
\end{tabular}

استرس از نظر جنسيت در زنان، از نظر سن در گروه سنّى

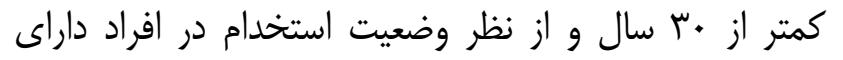

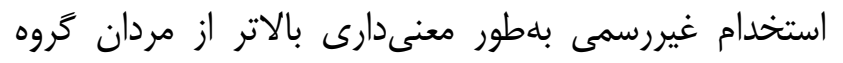

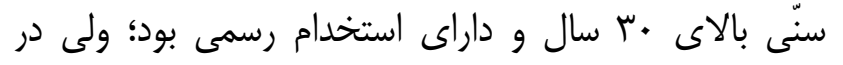

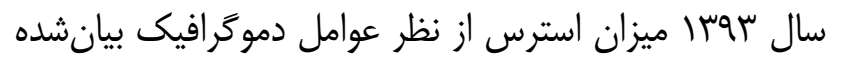

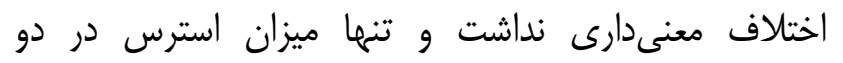
بيمارستان، اختلاف معنىدارى داشت كه شايد افزايش نيروى لني

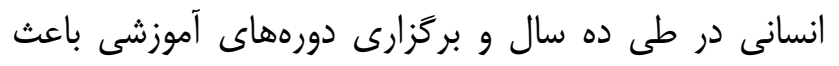

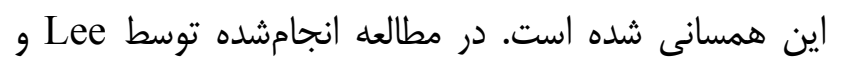

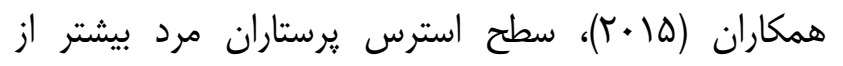

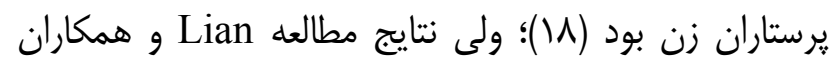

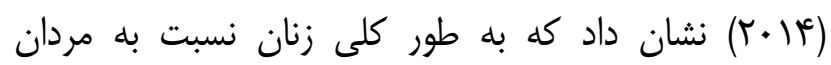
استرس كارى بيشترى را تجربه مى كنند كه همسو با نتايج

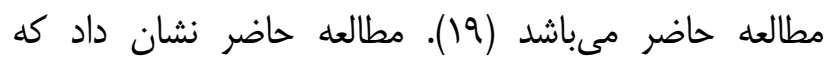

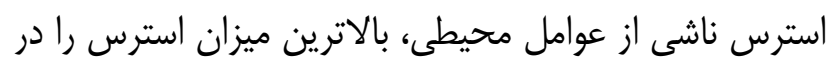

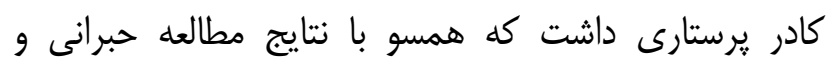

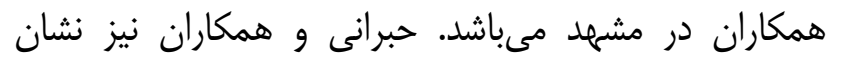

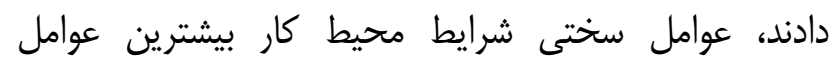

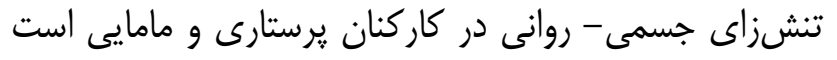

نتايج مطالعه حاضر نشان داد كه ميانگين استرس ناشى

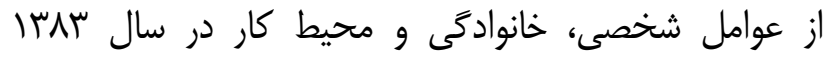

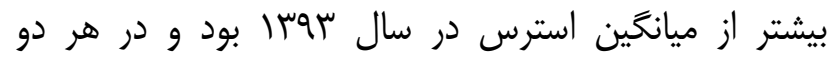
مطالعه عوامل استرسزاى محيط كار، بيشتر از عوامل
اين مطالعه با هدف بررسى انواع استرسهاى روانى - إنى اجتماعى كادر يرستارى بيمارستانهاى آموزشى شهر بيرجند

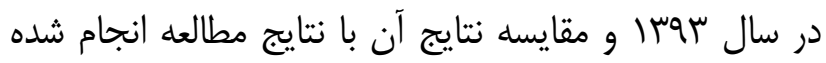

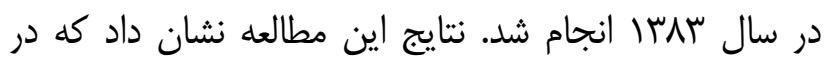
سال سوسا بـيش از بrدرصد كادر يرستارى داراى استرس شديد بودند كه در مقايسه با سال سریrا افزايش داشته است.

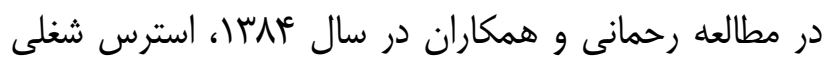

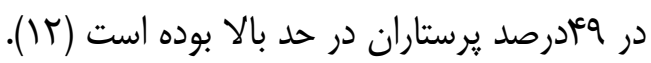
دامنه سطح استرس كم، در سال سوسا بيشتر از سال سرسا بود كه مىتواند به علت ايجاد زمينه مناسب از جمله

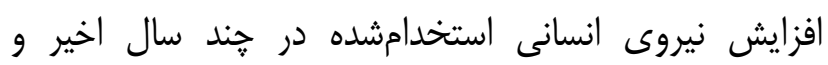
برگزارى دورههاى آموزشى و ... براى كادر يرستارى باشد.

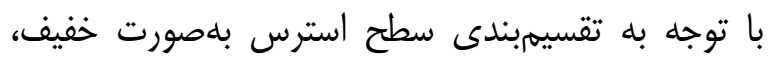

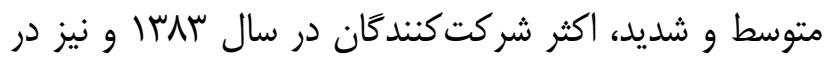
سال سوسا در سطح استرس متوسط قرار داشتند. مطالعه

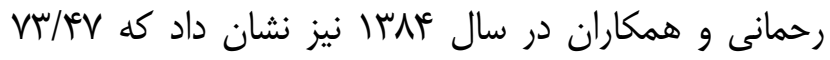
درصد يرستاران مورد بررسى، از نظر شدت استرس درس شغلى، در

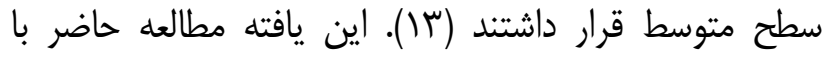
نتايج مطالعات ضيغمى محمدى، سـتوده اصـل، يروين و و

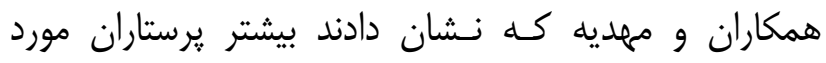
مطالعه آنها استرس متوسط داشتند، همـسو مىباشد (-IV)

نتايج يزوهش حاضر نشان داد كه در سال سیرا ميزان 
استرسزاى شخصى و خانوادگى بود. اين امر مىتواند به اين دو مطالعه دانست.

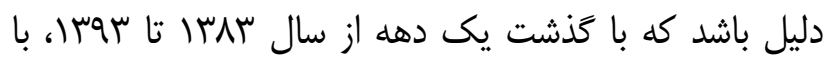

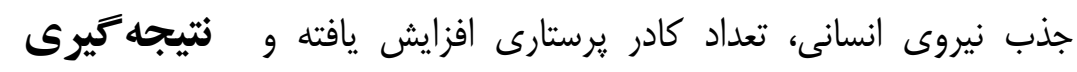
با توجه به نتايج بلددست آمده، بايد به مشكاتلات كادر يرستارى و بلخصوص وضعيت سلامت و بهداشت روان آنان

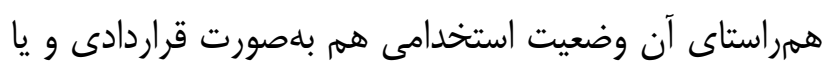

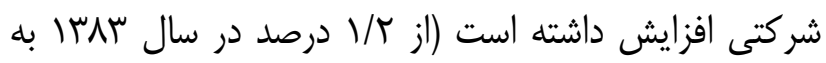

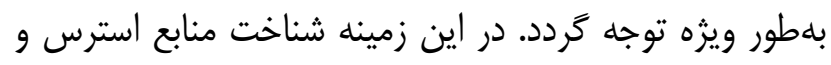

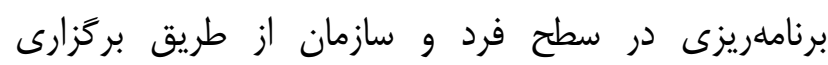

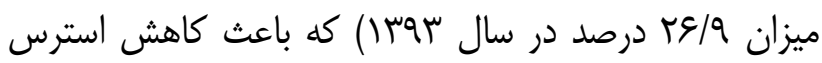
در طول اين دوره دهساله شده است.

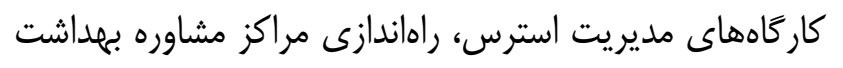

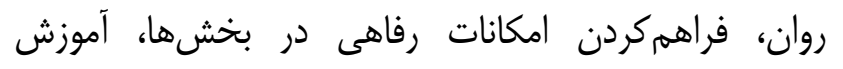

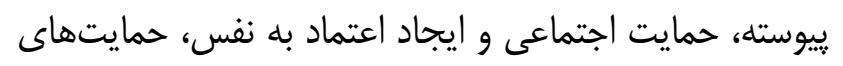

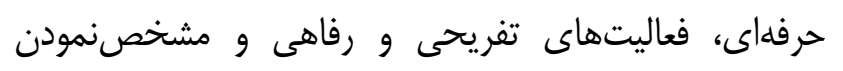

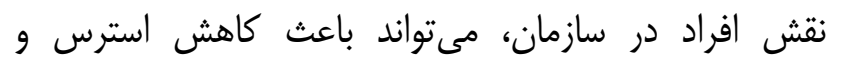
افزايش توانمندى كادر يرستارى شود.

\section{تقدير و تشكر}

بدينوسيله از معاونت محترم تحقيقات و فناورى دانشگاه علوم يزشكى بيرجند و از كليه كادر يرستارى و مديران

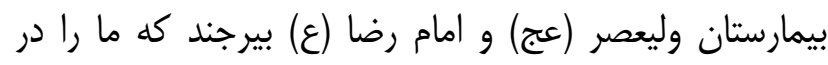

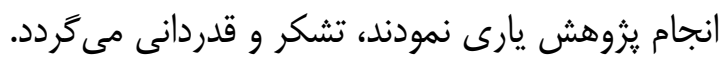

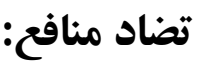

نويسندكان مقاله اعلام مى دارند كه هيجَّونه تضاد منافعى در

$$
\text { يزوهش حاضر وجود ندارد. }
$$

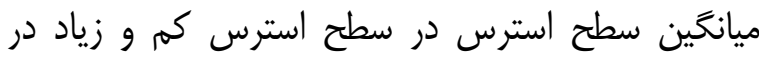

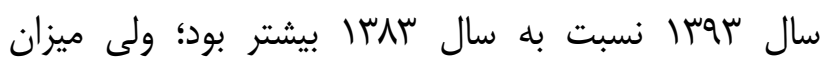
استرس در سطح متوسط در سال سربا بيشتر از سال سوسا بود كه مىتواند نشاندهنده بهبود عوامل ايجادكننده زمينه استرس در محيط كار و جامعه باشد. از طرفى كاهش تعداد

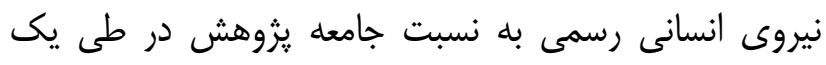

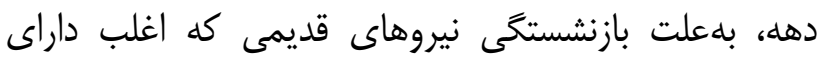
استخدام رسمى بودهاند (در سالهاى اخير اغلب كاركنان بلهصورت قراردادى و يا شركتى استخدام شدهاند)، مىتواند

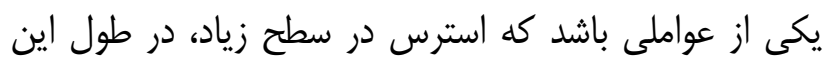
دهه افزايش يافته است.

با وجود يكسانبودن محيط كار، روش مطالعه و ... در دو يته

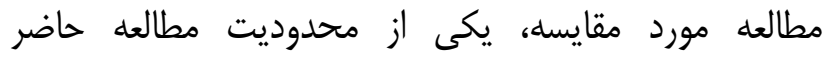

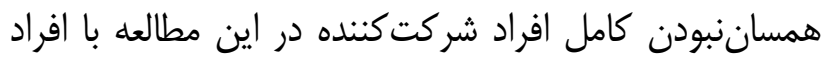

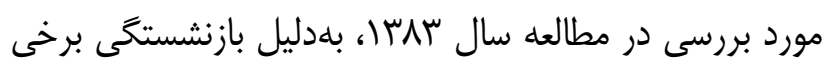
يرسنل و استخدام برسنل جديد در سال هاى اخير بود. بنابر اين

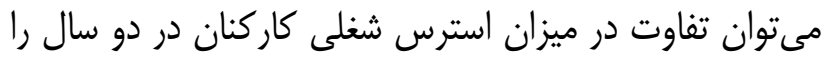
تا حدودى ناشى از تفاوت در مشخصات افراد شركت كننده در

منابع:

1- Rees CS, Breen LJ, Cusack L, Hegney D. Understanding individual resilience in the orkplace: the international collaboration of workforce resilience model. Front Psychol. 2015; 6: 73.

2- Azad-Marzabadi E, Hoshmndja M, Pourkhalili M. The relationship between organizational spirituality and spiritual intelligence and job stress a military university. Iran J Mil Med. 2013;15(1): 45-52.

3- Masoumy M, Tahmasebi R, Jalali M, Jafari S. The Study of the relationship between Job stress and spiritual health of nurses working in Intensive care ward at Bushehr Hospitals. Nursing Journal of the Vulnerable. 2016; 3(8): 37-47. [Persian]

4- Salehi Chaleshtari H. Evaluation of the effect of health education programs to reduce job stress in staff of Rahimi hospital of Freidoun-city [disseration]. Tehran: Tarbiat Modarres University; 2003. [Persian] 
5- Yildiz Findik U. Operating Room Nurses' Burnout and Safety Applications. International Journal of Caring Sciences. 2015; 8(3): 610-7.

6- Wu H, Chi TS, Chen L, Wang L, Jin YP. Occupational stress among hospital nurses: cross-sectional survey. J Adv Nurs. 2010; 66(3): 627-34.

7- Yaghoobnia F, Mazloom SR, Salehi Ghadrdy J, Esmaeili H. Study of Relationship Between Self-steem and burnout in Nurses of hospitals of Mashhad Univercity of Medical Sciences in 1379 (2000). J Sabzevar University of Medical Sciences. 2003; 10(3): 73-9. [Persian]

8- Tyson P, Pogruengphant R, Aggarwal B. Coping With organisationl stress among hospital nurses in Southern Ontario. Int J Nurs Stud. 2002; 39(4): 453-9.

9- Khghanizadeh M, Ebadi A, Cirati nair M, Rahmani M. The study of relationship between job stress and quality of work life of nurses in military hospitals. J Mil Med. 2008; 10(3): 175-84. [Persian]

10- Laudo J. Current Occupational \& Environmental Medicine. $3^{\text {rd }}$ ed. New York: McGraw Hill; 2001.

11- Tofighi A, Babaei S, Dastah S. The relationship between physical activity and mental health among nurses of urmia hospitals. J Urmia Nurs Midwifery Fac. 2014; 12(1): 72-78. [Persian]

12- Akbari F, Amirabadizadeh H, Poor Reza A, Vagheie Y, Dastjerdi R. Survey of socio-psychological stresses among nurses working in Birjand teaching hospitals in 2004. J Birjand Univ Med Sci. 2005; 12 (3 and 4): 9-15

13- Rahmani F, Behshid M, Zamanzadeh V, Rahmani F. Relationship between general health, occupational stress and burnout in critical care nurses of Tabriz teaching hospitals. Iran J Nurs. 2010; 23(66): 54-63. [Persian]

14- Zeighami Mohammadi Sh, Asgharzadeh Haghighi S. Relation between Job Stress and Burnout among Nursing Staff. Sci J Hamadan Nurs Midwifery Fac. 2011; 19(2): 42-52. [Persian]

15- SotudehAsl N, Bakhtiari AH. Occupational exhaustion and its related factors in nurses and midwives of Semnanuniversity of medical sciences. Sci J Kurdistan Univ Med Sci. 2006; 11(1): 77-83. [Persian]

16- Parvin N, Kazemian A, Hassan Poor A, Alavi A. Evaluation nurses, job stressors in Shahrekord hospitals affiliated to medical university in 2002. J Fac Nurs Midwifery, Birjand Univ Med Sci. 2005; 2(3-4): 31-6. [Persian]

17- Mahdieh O, Darvishi Ghazanchi S. The Study of the Relationship between Nurses' Job Stress and Resiliency. Quarterly Nurses and Physicians in Razm. 2017; 5(14): 17-22. [Persian]

18- Lee J. Job Stress and Stress Coping Strategies among Male and Female Korean Nurses. Adv Sci Technol Lett. 2015; 120: 692-5.

19- Lian SY, Tam CL. Work Stress, Coping Strategies and Resilience: A Study among Working Females. Asian Soc Sci. 2014; 10(12): 41-52.

20- Habrani P, Behdani F, Mobtaker M. Study of Stressors in Nurses. J Fundam Ment Health. 2008; 10(3): $231-7$. [Persian] 